\title{
Hydrophilic and amphiphilic water pollutants: using advanced analytical methods for classic and emerging contaminants
}

\author{
Walter Giger
}

Published online: 27 November 2008

(C) Springer-Verlag 2008

\begin{abstract}
Organic pollutants are a highly relevant topic in environmental science and technology. This article briefly reviews historic developments, and then focuses on the current state of the art and future perspectives on the qualitative and quantitative trace determination of polar organic contaminants, which are of particular concern in municipal and industrial wastewater effluents, ambient surface waters, run-off waters, atmospheric waters, groundwaters and drinking waters. The pivotal role of advanced analytical methods is emphasized and an overview of some contaminant classes is presented. Some examples of polar water pollutants, which are discussed in a bit more detail here, are chosen from projects tackled by the research group led by the author of this article.
\end{abstract}

Keywords Emerging contaminants $\cdot$ Liquid chromatography · Mass spectrometry · Surfactants . Antibiotics $\cdot$ Perfluorinated compounds $\cdot$ Benzotriazoles

\section{Introduction}

Since the early 1970s, organic substances have been determined as individual trace contaminants in the environ-

\footnotetext{
W. Giger

GRC, Giger Research Consulting,

8049 Zurich, Switzerland

W. Giger $(\triangle)$

Eawag, Swiss Federal Institute of Aquatic Science

and Technology,

8600 Dübendorf, Switzerland

e-mail: giger@eawag.ch
}

ment. Polarity-volatility diagrams - as shown in Fig. 1can be applied in order to get a systematic overview of the organic pollutants. Figure 1A depicts five coarse categories of organic environmental chemicals: volatile, semivolatile, nonpolar/lipophilic, polar/hydrophilic and amphiphilic substances. This categorization divides the "universe" of chemical contaminants into groups with comparable physicochemical environmental behavior. The constituents of a particular contaminant group can be determined using the same analytical techniques.

\section{Analytical methods}

The polarity-volatility plot can also be utilized to display the application ranges of the two most important separation techniques, gas chromatography (GC) and liquid chromatography (LC), which are very widely applied to resolve individual organic contaminants in the often very complex mixtures that occur in environmental samples (Fig. 1B). It should be noted that the two application ranges overlap substantially, i.e., both separation methods are feasible for many analytes. For nearly four decades, the prevailing focus in analytical environmental chemistry was on volatile and semivolatile nonpolar/lipophilic contaminants, because GC (the analytical tool predominantly employed) yields excellent separations for this type of pollutant. GC detectors with either universal characteristics (mainly the flame ionization detector, FID) as well as selective and sensitive detectors such as the electron capture detector (ECD) and the nitrogen-phosphorus detector (NPD) were crucially important. Even greater relevance should be attributed to gas chromatography directly coupled to mass spectrometry 


\section{a}

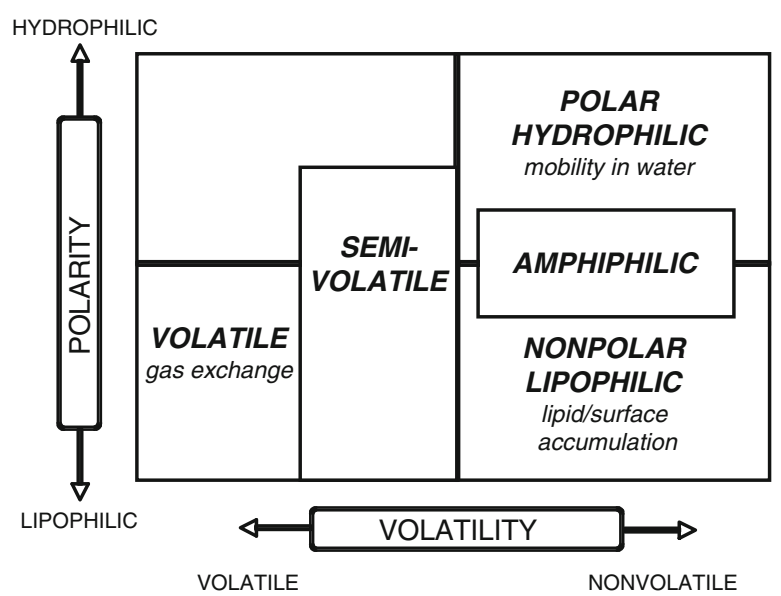

b

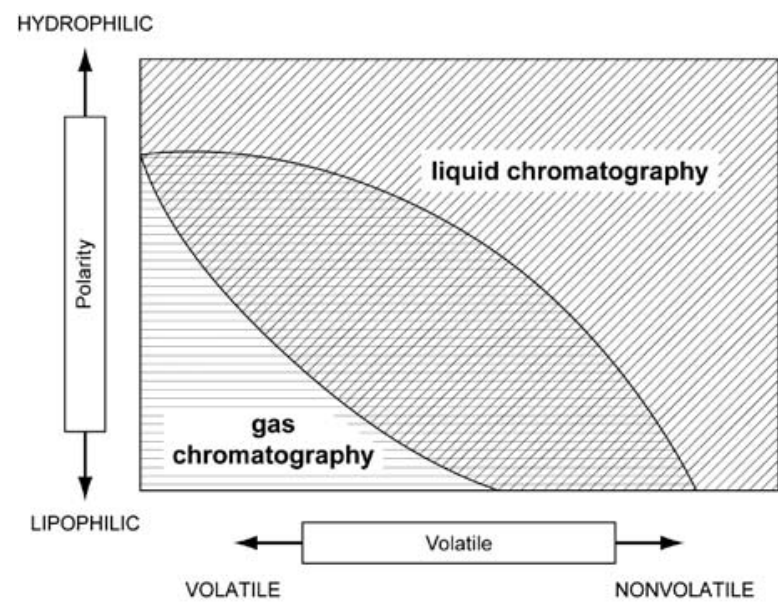

C

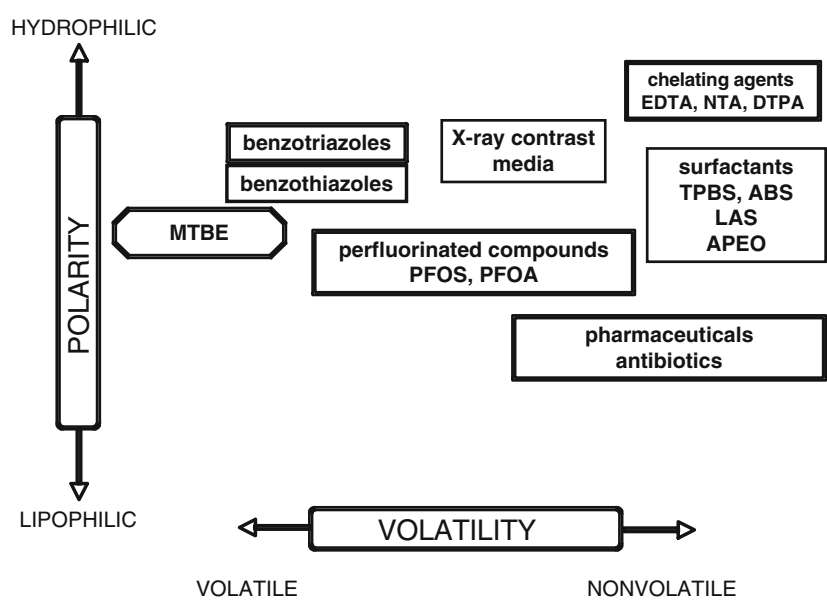

(GC/MS) for qualitative and quantitative determinations of volatile, semivolatile and lipophilic trace contaminants in the environment.

However, very polar and amphiphilic contaminants (e.g., EDTA, NTA, or anionic, nonionic and cationic surfactants)
Fig. 1 Polarity-volatility diagrams. A Coarse classification of organic pollutants indicating key processes (italics) that determine their fate and behavior in the environment without considering biotic and abiotic transformations. B Application ranges of gas and liquid chromatography, the crucial separation techniques applied to perform qualitative and quantitative determinations of individual organic pollutants. Separation techniques used for enrichment purposes, such as solid-phase extraction, liquid-liquid extraction, gaseous stripping, Soxhlet extraction or accelerated solvent extraction, are not shown. C Positions of polar contaminants in the polarity-volatility diagram. For definitions of acronyms, see Fig. 2 and Table 1

could only be determined by GC after the derivatization or transformation of the analytes to more volatile species. For a long time, amphiphilic substances (surfactants, surfaceactive agents) were almost always determined by collective parameters, without any separation into individual components. The introduction of high-performance liquid chromatography (HPLC) enabled the specific determination of several surfactant classes by ultraviolet absorption or fluorescence detection [1-4].

Since the mid-1990s, liquid chromatography (LC) directly coupled to mass spectrometry (LC/MS) has become a routinely applicable and robust method in the wake of the development of new ionization techniques such as electrospray ionization (ESI) and atmospheric pressure chemical ionization (APCI). LC/MS allows much better coverage of polar/hydrophilic and amphiphilic contaminants. Furthermore, the extremely high selectivity and sensitivity of multiple reaction monitoring techniques (MRM) in tandem or multistage quadrupole and ion-trap mass spectrometry (MSMS, $\mathrm{MS}^{\mathrm{n}}$ ) allow trace constituents of complex mixtures to be determined. Current analytical trends suggest that semivolatile and nonvolatile contaminants will be predominantly determined by LC/MSMS, and that multicomponent methods are applied across several compound classes.

Preconcentration of nonpolar and polar compounds is often based on solid-phase extraction for aqueous samples and on a variety of extraction procedures from solid samples (e.g., Soxhlet extraction, pressurized liquid extraction, microwave-assisted extraction, ultrasonic solvent extraction, etc.). Oasis HLB is a very popular SPE material for the extraction of highly polar analytes. The analytical trend for water samples is moving towards the application of online enrichment before LC separation or large-volume injection, which both profit greatly from the enormously high selectivity and sensitivity of tandem or multistage mass spectrometry. These methods are very advantageous due to their short analysis times, minimization of interferences and highly robust performances.

Richardson has published a series of excellent review articles in Analytical Chemistry on progress in the analysis of emerging contaminants [5, 6]. Barceló and Petrovic [7] 
have recently reviewed the achievements of LC/MS for environmental contaminants. Some important current instrumental and procedural developments include:

- Online solid-phase extraction (SPE-LC)

- Large-volume injection (LVI)

- Ultraperformance liquid chromatography (UPLC)

- High-resolution time-of-flight mass spectrometry (Q-TOF-MS)

- Two-dimensional LC/MS (LC/LC/MS)

- Two-dimensional GC/MS (GC/GC/TOF-MS)

- Triple-quadrupole and hybrid mass spectrometry:

- Triple-quadrupole MS (QqQ)

- Hybrid tandem mass spectrometry, linear ion trap

- Fourier transformation linear ion trap (LTQ Orbitrap)

\section{Contaminant types and substances}

Since the advent of sensitive LC/MSMS systems, analytical research on organic pollution in the aquatic environment has shifted emphasis towards polar contaminants. Important polar compound classes are plotted in Fig. 1C and listed in Table 1. Information on the origins and applications of these particular contaminants is also included in Table 1. Figure 2 shows the concentration ranges for some important polar pollutant classes that have been observed in treated wastewater effluents. The book Organic Pollutants in the Water Cycle-Properties, Occurrence, Analysis and Environmental Relevance of Polar Compounds [8], edited by T. Reemtsma and M. Jekel and published in 2006, contains a dozen excellent chapters written by leading experts in the field.

Since the pioneering studies by Ternes and coworkers in the mid-1990s, numerous articles have been published on the residual amounts of pharmaceuticals and personal-care products (PPCPs), including antibiotics and X-ray contrast media, in wastewaters and in natural waters. The 2002 publication by researchers of the United States Geological Survey became the best-cited article in Environmental Science and Technology [9]. A recent overview is presented in the book Human Pharmaceuticals, Hormones and Fragrances: The Challenge of Micropollutants in Urban Water Management [10]. This book summarizes the occurrence, analytics, removal of and environmental risk from pharmaceuticals and personal care products in wastewater, surface water and drinking water. The book covers all aspects of the fate and removal of PPCPs in the whole water cycle: consumption and occurrence, analytical methods, the legal background, environmental risk assessment, human and animal toxicology, source control options, wastewater and drinking water treatment, as well as indirect reuse.
Radjenovic [11] has recently overviewed the application of advanced mass spectrometric methods to study the fate and removal of pharmaceuticals in wastewater treatment. Zwiener [12] has reviewed the occurrence and analysis of pharmaceuticals and their transformation products in drinking water treatment.

\section{Antibiotics}

Most pharmaceuticals are found in natural waters in only very low concentrations. Despite this general finding, the question of what risks these traces of pharmaceuticals pose to aquatic ecosystems arises. Antibiotics are of particular interest, because we do not currently know whether their presence in natural waters contributes to the spread of antibiotic resistance in microorganisms. Some of the antibiotics are relatively polar and are not easily degradable substances.

Gobel et al. [13-15] developed analytical trace methods and performed mass balances in municipal wastewater treatment plants in order to assess the elimination of sulfonamides, macrolides and trimethoprim in mechanical-biological wastewater treatment. In accordance with consumption data, clarithromycin and sulfamethoxazole were the most predominant macrolide and sulfonamide, respectively, found in Swiss wastewater. In the case of sulfamethoxazole, including the amount present as the main human metabolite, $N^{4}$-acetylsulfamethoxazole, proved to be crucial. Significant elimination was not observed for any of the investigated compounds in primary treatment. During secondary treatment, the elimination observed depended on the treatment technology investigated. Overall, sorption to sludge was of minor importance for all of the compounds investigated. Different treatment technologies were investigated for secondary wastewater treatment in order to eliminate the selected compounds. Similar results were obtained in two conventional activated sludge systems and a fixed-bed reactor. While significant removal was not observed for trimethoprim, sulfamethoxazole (including the amount present as $N^{4}$-acetylsulfamethoxazole) was eliminated by about $60 \%$. Approximately $80 \%$ of the total sulfamethoxazole load was eliminated in the membrane bioreactor.

\section{Alkylphenolic compounds}

Nonylphenolpolyethoxylates (NPnEO) are surface-active substances (surfactants) with excellent wetting and solventenhancing properties. Among other uses, the nonionic surfactants NPnEO are applied as industrial cleaning agents and as textile auxiliaries. NPnEO are biologically degraded 
Table 1 Polar organic contaminants occurring in municipal and industrial wastewater effluents, ambient surface waters, ground waters and drinking waters

\begin{tabular}{|c|c|c|c|}
\hline Compound class & Substance & Uses, origins & $\begin{array}{l}\text { Literature } \\
\text { references }\end{array}$ \\
\hline \multirow[t]{7}{*}{$\begin{array}{l}\text { Surfactants and } \\
\text { metabolites }\end{array}$} & $\begin{array}{l}\text { Linear } \\
\text { alkylbenzenesulfonates } \\
\text { (LAS) }\end{array}$ & $\begin{array}{l}\text { Anionic surfactants } \\
\text { LAS accumulate in anaerobically digested } \\
\text { sewage sludge (approximately } 5 \mathrm{~g} / \mathrm{kg} \text { d.s.) }\end{array}$ & {$[26,27]$} \\
\hline & $\begin{array}{l}\text { Sulfophenylcarboxylates } \\
\text { (SPC) }\end{array}$ & LAS metabolites & {$[28]$} \\
\hline & $\begin{array}{l}\text { Alkylphenol } \\
\text { polyethoxylates (APEO) }\end{array}$ & $\begin{array}{l}\text { Nonionic surfactants } \\
\text { APEO degrade to more toxic and } \\
\text { endocrine-disrupting metabolites }\end{array}$ & \\
\hline & Nonylphenol (NP) & NPEO metabolite & \\
\hline & Octylphenol (OP) & OPEO metabolite & \\
\hline & $\begin{array}{l}\text { Nonylphenoxy acetic } \\
\text { acids (NPEC) }\end{array}$ & NPEO metabolite & \\
\hline & $\begin{array}{l}\text { Quaternary ammonium } \\
\text { compounds }\end{array}$ & & \\
\hline \multirow[t]{4}{*}{ Endocrine disruptors } & Steroidal hormones & Plasticizer & \\
\hline & Bisphenol A & NPEO metabolite & \\
\hline & Phthalates & & \\
\hline & Nonylphenol & & \\
\hline \multirow[t]{3}{*}{$\begin{array}{l}\text { Perfluorinated } \\
\text { compounds }\end{array}$} & $\begin{array}{l}\text { Perfluorooctanoic acid } \\
\text { (PFOA) }\end{array}$ & $\begin{array}{l}\text { Production of non-stick } \\
\text { and stain-resistant } \\
\text { coatings and products }\end{array}$ & {$[16]$} \\
\hline & $\begin{array}{l}\text { Perfluorooctanoic } \\
\text { sulfonate (PFOS) }\end{array}$ & & \\
\hline & $\begin{array}{l}\text { Perfluorobutanoic } \\
\text { sulfonate (PFBS) }\end{array}$ & & \\
\hline \multirow[t]{4}{*}{ Benzotriazoles } & Benzotriazole (BTr) & Corrosion inhibitor & {$[20,21,22]$} \\
\hline & Tolyltriazoles (TTr) & Aircraft de-icers & \\
\hline & Xylyltriazole & Dishwasher & \\
\hline & & Detergents & \\
\hline \multirow{3}{*}{ Benzothiazoles } & Benzothiazole (BT) & Fungicides & {$[8]$} \\
\hline & 2-Hydroxybenzothiazole & Vulcanization & \\
\hline & 2-Mercaptobenzothiazole & Accelerators & \\
\hline \multirow{3}{*}{$\begin{array}{l}\text { Aminopolycarboxylate } \\
\text { complexing agents }\end{array}$} & EDTA & & [29] \\
\hline & DTPA & & \\
\hline & NTA & & \\
\hline $\begin{array}{l}\text { Benzene- and } \\
\text { naphthalenesulfonates }\end{array}$ & $\begin{array}{l}\text { Naphthalene-1, } \\
\text { 5-disulfonate }\end{array}$ & & {$[8]$} \\
\hline \multirow{2}{*}{$\begin{array}{l}\text { Iodinated X-ray } \\
\text { contrast media }\end{array}$} & Amidotrizoate & & {$[30,31]$} \\
\hline & Iopamidol & & \\
\hline \multirow[t]{3}{*}{ Sulfonamides } & Sulfamethoxazole & Human and veterinary antibiotics & {$[15]$} \\
\hline & Benzenesulfonamide & & [32] \\
\hline & Toluolsulfonamide & & \\
\hline \multirow[t]{3}{*}{ Pharmaceuticals } & Carbamazepine & & {$[10]$} \\
\hline & Diclofenac & & \\
\hline & Clofibric acid & & \\
\hline \multirow{6}{*}{$\begin{array}{l}\text { Polar herbicides and } \\
\text { metabolites }\end{array}$} & Atrazine, simazine & & {$[33]$} \\
\hline & Glyphosphate & & {$[34]$} \\
\hline & AMPA & & \\
\hline & Metolachlor & & \\
\hline & Metolachlor-OXA, -ESA & & \\
\hline & Mecoprop & & \\
\hline Gasoline additives & MTBE & & \\
\hline \multirow[t]{2}{*}{ 1,4-Dioxane } & & & {$[35]$} \\
\hline & & & {$[36]$} \\
\hline \multirow{2}{*}{$\begin{array}{l}\text { Disinfection } \\
\text { by-products }\end{array}$} & Haloacetic acids & & \\
\hline & Nitrosodimethylamine (NDMA) & & \\
\hline Cyanobacteria toxins & Algal blooms & & {$[37]$} \\
\hline
\end{tabular}




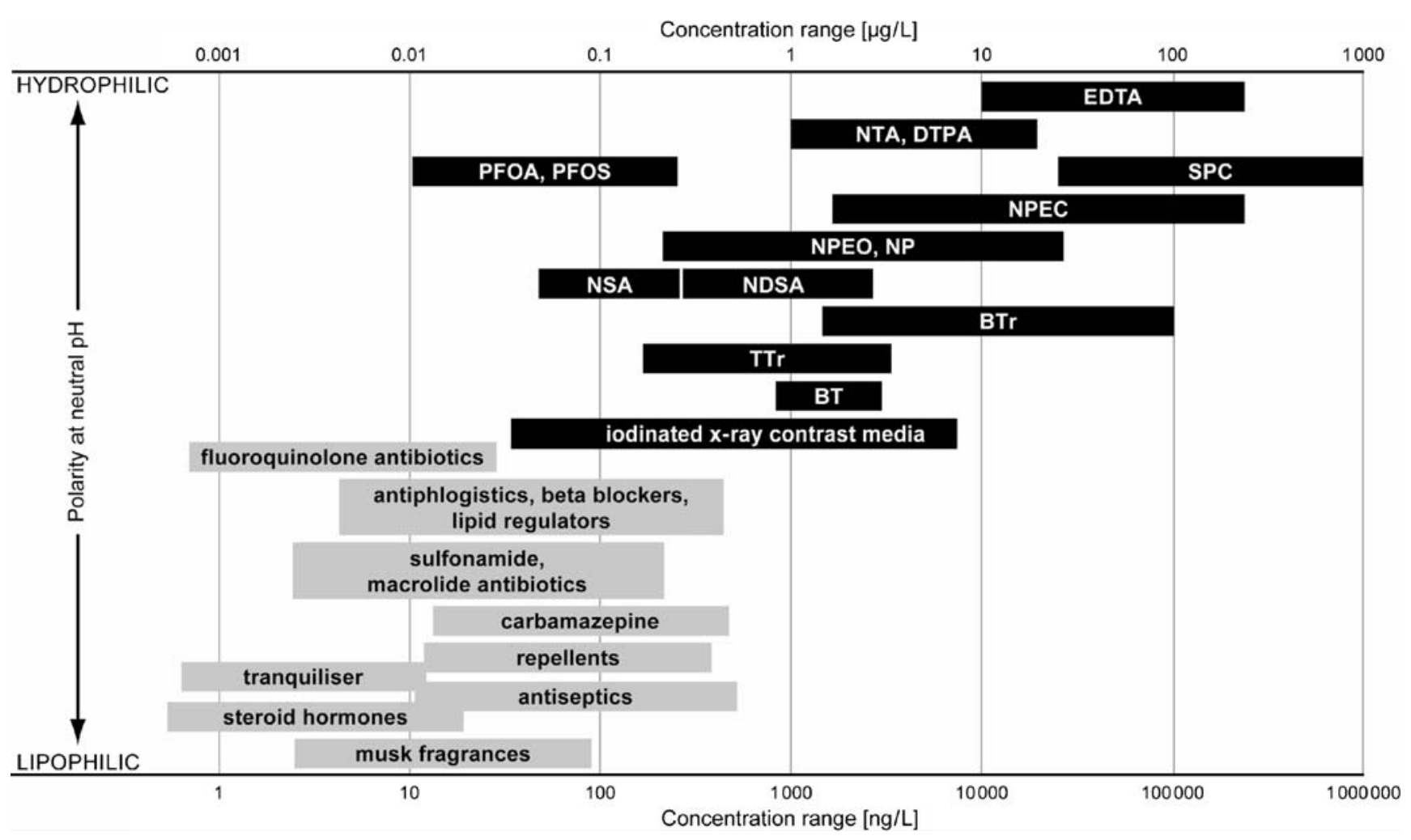

Fig. 2 Concentration ranges of polar organic contaminants in treated municipal wastewater effluents. EDTA, ethylenediaminetetraacetate; $D T P A$, propylenediaminetetraacetate; NTA, nitrilotriacetate; $L A S$, linear alkylbenzenesulfonates; $S P C$, sulfophenylcarboxylates; $B T r$, benzotriazole; TTr, tolyltriazoles; $B T$, benzothiazole; NPEO, non-

in mechanical-biological wastewater treatment. The significant metabolite nonylphenoxyacetic acid (NP1EC) is usually ten times more abundant than nonylphenol, nonylphenolmono- and diethoxylates in biologically treated wastewaters and in surface waters. Thus, the occurrence, fate and degradation of NP1EC in wastewaters and in surface water should be studied thoroughly, although NP1EC has a lower toxicity and is a less potent endocrine disruptor than NP. Wettstein [16] reported the results of an investigation into various nonylphenolic compounds in wastewater treatment with an emphasis on the formation and degradation of NP1EC. In the wastewater treatment plant investigated, a conventional activated sludge treatment in an aeration tank with a subsequent sand filter is operated parallel to a pilot plant using membrane technology. Concentrations of the nonylphenolpolyethoxylate surfactants in the primary effluent ranged from 60 to $220 \mu \mathrm{g} / \mathrm{L}$. In the conventional treatment, NP1EC is formed during biological treatment and then degraded in the sand filter (primary effluent: $3.2 \mu \mathrm{g} / \mathrm{L}$, secondary effluent: $4.7 \mu \mathrm{g} / \mathrm{L}$, tertiary effluent: $1.4 \mu \mathrm{g} / \mathrm{L}$ ). A laboratory-scale degradation experiment inoculated with a sample of sand filter material proved the aerobic degradation capacity of the sand filter for ylphenol polyethoxylates; $N P$, nonyphenols; $N P E C$, nonylphenoxycarboxylic acids; $P F O A$, perfluorooctanoic acid; $P F O S$, perfluorooctanoic sulfonate; NSA, naphthalenesulfonic acids; NDSA, naphthalenedisulfonic acids

NP1EC. Degradation experiments with NP1EC $(50 \mathrm{mg} / \mathrm{L}$ and $20 \mathrm{mg} / \mathrm{L}$ ) with activated sludge were performed in the laboratory. NP1EC was fully degraded in both experiments. An increase of NP was observed, and eventually complete degradation of NP occurred. In a degradation experiment under anaerobic conditions with digested sewage sludge, the degradation of NP1EC and the simultaneous formation of NP were observed [16].

A recent study by Jonkers et al. [17] focused on the occurrence and behavior in wastewater and surface waters of several phenolic EDCs, including parabens, alkylphenolic compounds, phenylphenol $(\mathrm{PhP})$ and bisphenol A (BPA). Analytical procedures using solid-phase extraction and LC/MSMS techniques were applied to samples of influents and effluents of wastewater treatment plants (WWTPs) discharging into the Glatt River (Switzerland), as well as to river water samples. A mass flow analysis provided insight into the main sources and the fates of these contaminants during different weather conditions. Concentrations in influents were in the low $\mu \mathrm{g} / \mathrm{L}$ range for most analytes. Removal of parabens in the WWTPs was mostly above $99 \%$. Nonylphenol polyethoxylate $\left(\mathrm{N}_{\mathrm{g}} \mathrm{PEO}\right)$ removal amounted to $98 \%$, but in some cases nonylphenoxy acetic 
acid $\left(\mathrm{N}_{\mathrm{g}} \mathrm{PEC}\right)$ or nonylphenols (NP) were formed. In effluents, concentrations were highest for the $\mathrm{N}_{\mathrm{g}} \mathrm{PEC}$, $\mathrm{N}_{\mathrm{g}} \mathrm{PEO}$ and NP. Concentrations in river water were in the high $\mathrm{ng} / \mathrm{L}$ range for nonylphenolic compounds and in the low ng/L range for BPA, PhP and the parabens. During the sampling period, in which several rain events occurred, both water flows and mass flows varied strongly. Mass flows in WWTP effluents and in the river increased with increasing water flows for most compounds, indicating that higher water flows do not lead to a proportional dilution of the pollutants. Throughout the low water flow period, mass flows predicted from the known inputs were similar to the actual mass flows at the end of the river for most analytes. Significant in-stream removal could not be observed for any of the EDCs. In the periods with high water flows, mass flows in the river were much higher than can be explained by the initially defined sources.

\section{Perfluorinated and polyfluorinated chemicals}

Perfluorinated and polyfluorinated chemicals (PFCs, fluorochemicals) are highly persistent contaminants that are globally distributed in air, water, and biota. Wastewater treatment plants (WWTP) play an important role in mitigating pollutant releases from municipalities to aquatic and terrestrial environments. However, because WWTPs are point sources of fluorochemicals, it is important to understand their contribution to fluorochemical burdens in the greater context of watersheds.

Schultz et al. [18] developed a quantitative method for the determination of fluorinated alkyl substances in municipal wastewater influents and effluents. The method consisted of centrifugation followed by large-volume injection $(500 \mu \mathrm{L})$ of the supernatant onto a liquid chromatograph with a reversed-phase column and detection by electrospray ionization and tandem mass spectrometry. The fluorinated analytes studied include perfluoroalkyl sulfonates, fluorotelomer sulfonates, perfluorocarboxylates and selected fluorinated alkyl sulfonamides. The lower limit of quantitation was $0.5 \mathrm{ng} / \mathrm{L}$, depending on the analyte. The method was applied to flow-proportional composites of raw influent and final effluent collected over a $24 \mathrm{~h}$ period from ten WWTPs nationwide. Fluorinated alkyl substances were observed in wastewater at all treatment plants, and each plant exhibited unique distributions of fluorinated alkyl substances despite similarities in the treatment processes. In nine out of the ten plants sampled, at least one class of fluorinated alkyl substances exhibited increased concentrations in the effluent compared to the influent concentrations. In some instances, decreases in certain fluorinated analyte concentrations were observed and attributed to sorption to sludge.
Huset et al. [19] have measured concentrations of eleven fluorochemicals from seven WWTPs that discharge effluent into the Glatt River in Switzerland compared to the measured mass flows within the Glatt River. Overall, the WWTPs did not remove fluorochemicals except for perfluorodecane sulfonate (PFDS). Effluents from WWTPs and Glatt River water were dominated by perfluorooctane sulfonate (PFOS), which was detected in all samples, followed by perfluorohexane sulfonate (PFHxS) and perfluorooctanoate (PFOA). The mass flows of fluorochemicals emanating from WWTPs were found to be conserved within the $35 \mathrm{~km}$ Glatt River, which indicates that the input from the WWTPs is additive and that removal within the Glatt River is not significant. Per capita discharges of fluorochemicals were calculated from the populations served by the WWTPs studied; the values determined also account for the fluorochemical content of Greifensee, which is a lake at the headwaters of the Glatt River that also receives treated wastewater.

\section{Benzotriazoles}

The complexing agents benzotriazole (BTri) and tolyltriazole (TTri) are not only widely applied as anticorrosives, e.g., in aircraft deicer and anti-icer fluids, but they are also used for so-called silver protection in dishwasher detergents. Due to their low biodegradability and limited sorption tendency, BTri and TTri are only partly removed in wastewater treatment. Residual concentrations of BTri and TTri were determined in ambient surface waters in Switzerland, including seven rivers which have distinct water flows and receive treated wastewater effluents at various dilution ratios $[20,21]$. A maximum BTri concentration of $6.3 \mu \mathrm{g} / \mathrm{L}$ was found in the Glatt River, and a maximum mass flow of $277 \mathrm{~kg}$ BTri per week was observed in the Rhine River. In most cases, TTri was about 5-10 times less abundant. During winter 2003/4, BTri mass flows at two locations in the lower stretch of the Glatt River clearly indicated the input from nearby Zurich airport, where BTri was applied as an anticorrosive ADAF component. BT concentrations measured in the three lakes Greifensee, Zurich and Geneva were approximately 1.2, $0.1-0.4$, and $0.2 \mu \mathrm{g} / \mathrm{L}$, respectively. The observed environmental occurrences indicate that BTri and TTri are ubiquitous contaminants in the aquatic environment and that they belong to the most abundant individual water pollutants. Weiss and Reemtsma [22, 23] separated benzotriazole (BTri) and the two isomers of tolyltriazole (5- and 4-TTri) in an isocratic run. BTri, 4-TTri, 5-TTri, and xylyltriazole can be determined by gradient elution simultaneously with three benzothiazoles, but in this case TTri isomers coelute. The instrumental detection limit of $2 \mathrm{pg}$ 
allows the determination of the three most important benzotriazoles from municipal wastewater and most surface waters by direct injection into the HPLC system without previous enrichment. When solid-phase extraction is employed with mean recovery rates of $95-113 \%$, the limits of quantification for benzotriazoles range from $10 \mathrm{ng} / \mathrm{L}$ in groundwater to $25 \mathrm{ng} / \mathrm{L}$ in untreated wastewater. BTri and TTri were determined in municipal wastewater in microgram per liter concentrations. Elimination in wastewater treatment appears to be poor, and BTri and TTri can be followed through a water cycle from treated municipal wastewater through surface water to bank filtrate used for drinking water production. The TTri isomers show markedly different biodegradation behaviors, with 4-TTri being the most stable.

\section{Outlook and future challenges}

The new low-calorie sweetener sucralose, a polychlorinated glucose (1,6-dichloro-1,6-dideoxy- $\beta$-D-fructofuranosyl-4chloro-4-deoxy- $\alpha$-D-glucopyranoside), was recently registered as a food additive in Norway. One year after its introduction, it was found in sewage water at a level of several hundreds of $\mathrm{ng} / \mathrm{L}$, as determined by LC-TOF MS $[24,25]$. Little has been published on the possible environmental effects of sucralose, and environmental considerations do not seem to be included in the registration of food additives. However, published data indicate a half-life of well over a year in surface water, even though sucralose is very hydrophilic. Although toxicity does not seem to be a problem, the longevity of the compound may be of environmental concern. Several biological communication and orientation systems in aquatic ecosystems are based on taste. The accumulation of high concentrations of a very persistent compound with a distinct taste may therefore pose a future environmental problem that is not presently covered by the regulatory process. Almost no information is available on the environmental fates of other popular artificial sweeteners.

Nanomaterials, defined as engineered objects with characteristic dimensions that are smaller than $100 \mathrm{~nm}$, are being produced in growing quantities, with applications ranging from composite materials for tires to medical imaging. The most prominent carbon-based nanomaterials are caged fullerenes, such as C60 buckyballs and carbon nanotubes, which exhibit negligible solubility in water. However, these materials may be modified, intentionally or inadvertently, to increase their affinity with the aqueous phase, by functionalization or the adsorption of compounds such as surfactants. In addition, stable colloidal suspensions may be formed from modified or unmodified material. These colloids can show an envi- ronmental behavior similar to hydrophilic contaminants. It can be expected that these engineered nanomaterials will enter the aquatic environment in some way or another. Thus, it is important to develop sensitive and selective analytical methods for them.

It is foreseeable that, in the future, advanced analytical methodology will also lead to progress in environmental analysis, including water, air, soil and biota analyses. While they currently play a minor role due to the high specificity of LC/MSMS techniques based on multireaction monitoring, it can be expected that nontarget analyses will again become highly relevant for polar and amphiphilic water pollutants. The simultaneous measurement of as many analytes as possible will be a key methodology, in combination with online enrichment or direct injection procedures.

\section{References}

1. Ahel M, Giger W (1985) Anal Chem 57:2584-2590

2. Ahel M, Giger W (1985) Anal Chem 57:1577-1583

3. Marcomini A, Giger W (1987) Anal Chem 59:1709-1715

4. Ahel M, Giger W, Molnar E, Ibric S (2000) Croat Chem Acta 73:209-227

5. Richardson SD (2007) Anal Chem 79:4295-4323

6. Richardson SD (2008) Anal Chem 80:4373-4402

7. Barcelo D, Petrovic M (2007) Trends Anal Chem 26:2-11

8. Reemtsma T, Jekel M (2006) Organic pollutants in the water cycle: properties, occurrence, analysis and environmental relevance of polar compounds. Wiley-VCH, Weinheim

9. Kolpin DW, Furlong ET, Meyer MT, Thurman EM, Zaugg SD, Barber LB, Buxton HT (2002) Environ Sci Technol 36:12021211

10. Ternes TA, Joss A (eds) (2006) Human pharmaceuticals, hormones and fragrances. IWA, London

11. Radjenovic J, Petrovic M, Barcelo D (2007) Trends Anal Chem 26:1132-1144

12. Zwiener C (2007) Anal Bioanal Chem 387:1159-1162

13. Gobel A, McArdell CS, Suter MJF, Giger W (2004) Anal Chem 76:4756-4764

14. Gobel A, Thomsen A, McArdell CS, Joss A, Giger W (2005) Environ Sci Technol 39:3981-3989

15. Gobel A, McArdell CS, Joss A, Siegrist H, Giger W (2007) Sci Total Environ 372:361-371

16. Wettstein F (2004) PhD Thesis, ETH, Nr 15315

17. Jonkers N, Kohler H-PE, Dammhäuser A, Giger W (2009) Environ Poll (in press)

18. Schultz MM, Higgins CP, Huset CA, Luthy RG, Barofsky DF, Field JA (2006) Environ Sci Technol 40:7350-7357

19. Huset CA, Chiaia AC, Barofsky DF, Jonkers N, Kohler H-PE, Ort C, Giger W, Field JA (2008) Environ Sci Technol 42:6369-6377

20. Giger W, Schaffner C, Kohler HPE (2006) Environ Sci Technol 40:7186-7192

21. Voutsa D, Hartmann P, Schaffner C, Giger W (2006) Environ Sci Pollut Res 13(5):333-341

22. Weiss S, Reemtsma T (2005) Anal Chem 77(22):7415-7420

23. Weiss S, Jakobs J, Reemtsma T (2006) Environ Sci Technol 40:7193-7199

24. Dye C, Kylin H, Schlabach M (2008) Environ Sci Technol submitted 
25. Lubick N (2008) Environ Sci Technol 42:3125-3125

26. Knepper TP, Eichhorn P (2006) In: Reemtsma T, Jekel M (eds) Surfactant metabolites in organic pollutants in the water cycle. Wiley-VCH, Weinheim, pp 211-250

27. Ahel M, Molnar E, Ibric S, Giger W (2000) Water Sci Technol 42:15-22

28. Clara M, Scharf S, Scheffknecht C, Gans O (2007) Water Res 41:4339-4348

29. Schmidt CK, Brauch H-J (2006) In: Reemtsma T, Jekel M (eds) Aminocarboxylate complexing agents in organic pollutants in the water cycle. Wiley-VCH, Weinheim, pp $155-180$

30. Putschew A, Jekel M (2006) In: Reemtsma T, Jekel M (eds) Iodinated $\mathrm{x}$-ray contrast media in organic pollutants in the water cycle. Wiley-VCH, Weinheim, pp 87-98
31. Ternes TA, Hirsch R (2000) Environ Sci Technol 34:2741-2748

32. Richter D, Massmann G, Dunnbier U (2008) Chemosphere 71:1574-1581

33. Fobbe R, Kuhkmann B, Jürgen N, Preuss G, Skark C, ZulleiSeibert N (2006) In: Reemtsma T, Jekel M (eds) Polar herbicides and metabolites in organic pollutants in the water cycle. Wiley$\mathrm{VCH}$, Weinheim, pp 121-154

34. Moran MJ, Zogorski JS, Squillace PJ (2005) Ground Water 43:615-627

35. Isaacson C, Mohr TKG, Field JA (2006) Environ Sci Technol 40:7305-7311

36. Zwiener C (2006) In: Reemtsma T, Jekel M (eds) Polar herbicides and metabolites in organic pollutants in the water cycle. WileyVCH, Weinheim, pp 251-286

37. Svrcek C, Smith DW (2004) J Environ Eng Sci 3:155-185 